\title{
Factors Associated with PTSD in Cases of Sexual Assault
}

\author{
Adnan Çelikel ${ }^{1}$, D.Sümeyra Demirkiran ${ }^{1}$, Sait Özsoy ${ }^{2}$, Cem Zeren ${ }^{1}$, M.Mustafa Arslan ${ }^{1}$ \\ ${ }^{1}$ Mustafa Kemal University, Medical Faculty, Department of Forensic Medicine, Hatay/Turkey \\ ${ }^{2}$ Gülhane MilitaryMedical Academy, Department of Forensic Medicine, Ankara/Turkey \\ ${ }^{*}$ Corresponding author: Adnan Çelikel, Mustafa Kemal University, Medical Faculty, Department of Forensic Medicine, Hatay/Turkey, Tel: 905055497010; E-mail: \\ celikeladnan@yahoo.co.uk
}

Received Date: June10, 2014, Accepted Date: October 8, 2014, Published Date: October 15, 2014

Copyright: (c) 2015, Adnan Çelikel et al., This is an open-access article distributed under the terms of the Creative Commons Attribution License, which permits unrestricted use, distribution, and reproduction in any medium, provided the original author and source are credited.

\section{Abstract}

Aim: Acute stress disorder, depression and post-traumatic stress disorder (PTSD) can be seen in people who have been sexually assaulted. The aim of this study is to evaluate the socio-demographic characteristics of cases that are exposed to sexual assault and their relationship with PTSD.

Materials and Methods: The forensic reports of 175 sexual assault cases were analyzed retrospectively who were assessed in terms of physical and mental health disorders by Hatay Forensic Medicine Directorate between January 2011-March 2013.

Results: Of all victims, $143(81,7 \%)$ were female and $32(18,3 \%)$ were male. The ages of cases were ranged between 1 and 71 (median: male: 12, female: 16). It was determined that PTSD was developed in 47 victims after sexual assault and 3 cases were referred to a higher center. Sexual assaults were occurred more often in the home environment and victims were assaulted by people they knew ( $\mathrm{n}: 123,70,3 \%)$. PTSD development was significantly higher in victims who were assaulted by anal and vaginal route $(p<0,001)$. There was no significant difference in the presence of PTSD between male and female victims. However it is observed that presence of PTSD increases with age $(p<0,05)$.

Conclusion: As a conclusion it is found that sexual assault by anal and vaginal region and older ages are the significant risk factors for development of PTSD.

Keywords: Sexual assault; PTSD; Risk factors; Forensic medicine

\section{Introduction}

Although the most of sexual assault victims are women, both male and female children can be targeted. $13-20 \%$ of women and $3-4 \%$ of men in the world is reported to be sexually assaulted during their life $[1,2]$.

Sexual assault is a traumatic event that diminish one's harmony between his or her personality and environment. A very intense fear is experienced during the assault caused by violation of the one's body integrity and even endangering of his or her life. Different psychiatric diseases, mainly acute stress disorder, depression and post-traumatic stress disorder (PTSD) can be seen in people following a sexual assault exposure [3-5]. PTSD which was termed "rape trauma syndrome" formerly can be seen in soldiers after war or due to childhood physical and sexual abuse, domestic violence or following a variety of traumatic event such as, war, migration, natural and industrial disasters [6-10].

Insomnia, anxiety, fear response, nightmares and dissociative symptoms are seen in PTSD cases. Furthermore these symptoms are more severe and last longer, respectively when the source of stress is human, like in sexual assault event $[3,11,12]$.

PTSD is an anxiety disorder, characterized by re-experiencing symptoms, avoidance from trauma related objects, emotional dullness, overreacting to stress factors and also can be accompanied by behavioral disorders [13].
The aim of this study is to describe the characteristics of factors associated with PTSD cases who were exposed to sexual assault in the province of Hatay.

\section{Material and Method}

In our study, all forensic reports of sexual assault cases written byHatay Forensic Medicine Directorate between January 2011 and March 2013, were analyzed retrospectively. Total number of cases was 175 and they were evaluated in terms of physical and mental health. The reports were read and analyzed by authors in agreement with Hatay Forensic Medicine Directorate. Cases were assessed according to their age, gender, assault feature, assault place and relation between victim and offender.

Obtained data were analyzed by using SPSS for Win Ver. 16.0 (SPSS Inc. Chicago, IL., USA) package statistical software. Descriptive statistics were shown in numbers and percentages. The differences between groups were shown by using chi-square distribution and logistic regression test. $\mathrm{P}$ values less than 0,05 are accepted as statistically significant.

\section{Results}

Total number of sexual assault victims was 175 who were evaluated in terms of mental health between January 2011 and March 2013. Most of them were women $(81.7 \%, \mathrm{n}=143)$ and they were between 4 and 71 years of age (median: 16$)$. There were $32(18,3 \%)$ male victims. 
Page 2 of 4

They were between 1 and 22 years of age. (Median: 12) Of all offenders, $53,7 \%$ were known by the victim. When the offenders, who were relatives of the victim are added the number was $70,3 \%$. Ratio of unknown offenders were $26,3 \%$ (Table 1) Sexual assault mostly took place at home $(51,4 \% \mathrm{n}: 90)$ then second mostly took place in the streets and bazaar $(12,6 \% \mathrm{n}: 20)$ followed by open lands $(6,9 \% \mathrm{n}: 12)$. When we look for the presence of PTSD concerning connection between victim and offender there were no significant relation ( $>0.05)$ (Table 2).

\begin{tabular}{|l|l|l|}
\hline Relationship & N & $\%$ \\
\hline Undefined & * & 3,4 \\
\hline Known one & 94 & 3,4 \\
\hline Relative** $^{*}$ & & \\
\hline 1st degree & 18 & 10,3 \\
\hline 2nd degree & 11 & 6,3 \\
\hline Unknown & 46 & 26,3 \\
\hline TOTAL & 175 & 100 \\
\hline
\end{tabular}

Table 1: Relation between victim and offender, ${ }^{*}$ There is no information about the relationship between victim and offender, ${ }^{*}$ Uncle, brother, brother in law, father in law, father, step father, husband

\begin{tabular}{|l|l|l|l|}
\hline PTSD & $\begin{array}{l}\text { 1st and 2nd } \\
\text { degree } \\
\text { relative }\end{array}$ & $\begin{array}{l}\text { Not relative (including } \\
\text { known \& unknown people) }\end{array}$ & Total \\
\hline $\begin{array}{l}\text { not } \\
\text { Diagnosed }\end{array}$ & 17 & 108 & 125 \\
\hline & $63,0 \%$ & $74,5 \%$ & $72,7 \%$ \\
\hline Diagnosed & 10 & 37 & 47 \\
\hline & $37,0 \%$ & $25,5 \%$ & $27,3 \%$ \\
\hline TOTAL & 27 & 145 & 172 \\
\hline
\end{tabular}

Table 2: PTSD ratio concerning victim- offender relations, ${ }^{\star}$ Three cases were excluded since they are referred to another center

When we look for the relationship between presence of PTSD and property of sexual assault, PTSD was mostly diagnosed at one's who are exposed to anal penetration. $(\mathrm{p}<0.001)$ (Table 3). Presence of PTSD, in male victims was $28.1 \%$ ( $\mathrm{n}: 9)$ and in female victims was $27,1 \%$ (n:38). Male victims were not diagnosed PTSD in 71,9\% (n:23) and female victims were not diagnosed PTSD in 72,9\% (n:102).So there is not statistically significant difference between genders in terms of PTSD following sexual assault. ( $p>0,05)$. It is noticed that prevalence of PTSD increases as the age of the victim increases. Diagnosis of PTSD in older ages is significantly higher than the younger ages. $(\mathrm{p}<0,05)($ Table 4$)$

\begin{tabular}{|l|l|l|l|l|l|}
\hline PTSD & Property of Sexual Assault & & & & P \\
\hline & Molestation $(\mathbf{n} \%)^{*}$ & Anal $(\mathbf{n} \%)$ & Vaginal $(\mathbf{n} \%)$ & Anal+Vaginal $(\mathbf{n} \%)$ & \\
\hline Not diagnosed & $80(69,0 \%)$ & $11(9,5 \%)$ & $22(19,0 \%)$ & $3(2,6 \%)$ & 0,001 \\
\hline Diagnosed & $9(19,1 \%)$ & $12(25,5 \%)$ & $22(46,8 \%)$ & $4(8,5 \%)$ & \\
\hline
\end{tabular}

Table 3: Relation of PTSD and property of sexual assault, ${ }^{*}$ Rape attempt, kissing, touching, sexual verbal disturbance, ${ }^{\star *}$ Nine cases with unknown properties and three who are referred to a different center were excluded

\begin{tabular}{|l|l|l|l|}
\hline Age group (years) & $\begin{array}{l}\text { Positive } \\
(\mathbf{n} / \%)\end{array}$ & Negative (n/\%) & Total $(\mathbf{n} / \%)$ \\
\hline$<12$ & 6 & 51 & 57 \\
\hline & $(10,5 \%)$ & $(89,5 \%)$ & $(33,1 \%)$ \\
\hline $13-18$ & 24 & 44 & 68 \\
\hline & $(35,3 \%)$ & $(64,7 \%)$ & $(39,5 \%)$ \\
\hline $19-30$ & 14 & 24 & 38 \\
\hline & $(36,8 \%)$ & $(63,2 \%)$ & $(22,1 \%)$ \\
\hline$>30$ & 6 & 3 & 9 \\
\hline TOTAL & $50(29 \%)$ & $122(71 \%)$ & $172(100 \%)$ \\
\hline
\end{tabular}

\begin{tabular}{|l|l|l|}
\hline & Odds ratio $(\mathbf{9 5} \% \mathbf{C l})$ & $\mathbf{P}$ \\
\hline Age & $0,973(0,927-1,021$ & 0,257 \\
\hline Sex & $0,906(0,309-2,655)$ & 0,857 \\
\hline Property of assault & $8,966((3,576-22,478)$ & 0,000 \\
\hline Place of assault & $0,461(0,150-1,420)$ & 0,177 \\
\hline Victim- offender relation & $0,413(0,141-1,205)$ & 0,105 \\
\hline
\end{tabular}

Table 5: Multivariate logistic regression analysis of variables potentially associated with PTSD

\section{Discussion}

Almost all studies about sexual assaults show that victims are

Table 4: PTSD according to ages

When logistic regression analysis is performed, it is seen that, penetrative assaults are significantly related to development of PTSD (Table 5) mostly female and majority of them are less than 20 years of age. The offenders are mostly known by the victim and the place is generally a house [14-19]. In our study $81.7 \%(n=143)$ of the victims are female. Median age of the men is 12 and median age of the women is 16 . Most of the offenders $(70,3 \%)$ are known by the victims and assault primarily took place at home. Our findings are in concordance with 
Page 3 of 4

literature. According to various studies, life time PTSD prevalence is $7,8 \%$ and it is mostly diagnosed on rape victims with $57.1 \%$ [12,20-22]. In our study, the diagnosis of PTSD is significantly higher on penetrative sexual assault victims than others. Therefore PTSD formation increases when the sexual assault is more severe.

Presenting psychiatric diseases following a sexual assault is seen on women more than men according to many studies [20, 23-26]. One study showed that there is no difference between two sexes in terms of developing PTSD after sexual assault [27]. In our study prevalence PTSD following a sexual assault was same in both male and female victims. Psychiatric symptoms are seen more in adolescence if the offender is a relative of the victim or assault had been repeated more than once [28]. A study in USA showed that people who are sexually assaulted by their relatives had more psychiatric diseases [29]. One another study on women prisoners showed that younger women are more prone to be diagnosed as PTSD than elders following trauma [27]. Karbeyaz at al. documented a significant relationship between PTSD diagnosis and age disparity between victim and offender and also connection of victim and offender. When the age disparity between victim and offender was less than 5, PTSD was less frequently diagnosed. PTSD is highly seen on victims who are assaulted by a family member (incest). On the other hand PTSD is much less frequently seen when the assault was from a lover like boyfriend or fiancée [19]. In our study there is no interaction between PTSD and victim-offender relationship. However we found that as the age increased the prevalence of PTSD also increased. (Table 4) We think that it is because, elder are more aware about atrocity of the event and more affected by social and familial responses. Or it is because children are less affected due to lack of mental and intellectual maturity.

It is reported that an important determinant of PTSD is the given meaning for the trauma. As it changes personally PTSD is not seen on everybody following every trauma. Since the traumatic events are both in relation with each other and previous traumas, diagnosis of PTSD is still controversial on clinics. Determining the prognosis of PTSD is difficult because of the nature and variety of traumas and special meanings denoted by victim on them [30-32]. Karbeyaz at al. documented that; when the cases are evaluated in a local hospital $62,2 \%$ (n:168) of the cases are diagnosed as PTSD, however when they are evaluated by Institute of Forensic Medicine only 8 of those diagnosis are confirmed [19]. It is thought that, the high frequency of PTSD diagnosed by local hospitals is a result of limited time for diagnoses and treatment. The cases analyzed in our study were evaluated by a forensic medicine specialist with consultation from a psychiatrist and 47(27,3\%) of 172 cases were diagnosed PTSD.

Physical findings following a sexual assault can disappear soon after the event therefore psychiatric findings are sometimes more valuable than physical findings $[28,33,34]$.

Another study offer PTSD to be accepted as criminal evidence for sexual assaults in lack of physical evidences. PTSD is reported to become chronic in only the cases under existing effect. It implies, when evaluating the existing effects of the trauma; individual differences among the relationships between shape of the event on one's mind and his or her autobiography are important [12,22,23]. Therefore in terms of PTSD, examinations and treatments of victims after the assault should be done by professional units and be repeated when necessary.

\section{Limitations}

There were no psychiatrics records of cases prior to sexual assault which would be helpful for a better approach. And lack of structured diagnostic interviews of cases according to DSM V criteria was also a limitation for the study.

\section{Conclusion}

Posttraumatic stress disorder following a sexual assault is significantly higher when the penetrative intercourse is accomplished. PTSD is increased as the age of the victim increases and children victims are diagnosed significantly less than adolescents and adults. There is not any correlation between PTSD and victim-offender relationship and PTSD prevalence after sexual assault is almost same for both sexes.

\section{References}

1. Cook RJ, Dickens BM, Thapa S (2005) Caring for victims of sexual abuse. Int J Gynaecol Obstet 91: 194-199.

2. Danielson CK, Holmes MM (2004) Adolescent sexual assault: an update of the literature. Curr Opin Obstet Gynecol 16: 383-388.

3. Moscarello R (1990) Psychological management of victims of sexual assault. Can J Psychiatry 35: 25-30.

4. The American College of Obstetricians and Gynecologists Technical Bulletin (1993) Sexual Assault. Int Gynecol Obstet 42: 67-72.

5. Gölge ZB (2005) Psychological problems occurringafter sexual trauma. Archives of Neuropsychiatry 42: 19-28.

6. Ackerman PT, Newton JEO, McPherson WB, Jones JG, Dykman RA (1998) Prevalence of post-traumatic stress disorder and other psychiatric diagnoses in three groups of abused children (sexual, physical, and both). Child Abuse Negl 22: 759- 74.

7. Kendall-Tackett KA, Williams LM, Finkelhor D (1993) Impact of sexual abuse on children: a review and synthesis of recent empirical studies. Psychol Bull 113: 164-180.

8. Fischbach RL, Herbert B (1997) Domestic violence and mental health: correlates and conundrums within and across cultures. Soc Sci Med 45: 1161-1176.

9. Momartin S, Silove D, Manicavasagar V, Steel Z (2004) Comorbidity of PTSD and depression: associations with trauma exposure, symptom severity and functional impairment in Bosnian refugees resettled in Australia. J Affect Disord 80: 231-238.

10. Bryant RA, Harvey AG (1995) Psychological impairment following motor vehicle accidents. Aust J Public Health 19: 185-188.

11. Burgess AW, Fawcett J, Hazelwood RH (1995) Victim care services and comprehensive sexual assesment tool. In: Hazelwood RH, Burgess AW,eds. Rape investigation, 2nd edition, Boca Raton:CRC Press pp: 263-73

12. Javidi H, Yadollahie M (2012) Post-traumatic Stress Disorder. Int J Occup Environ Med 3: 2-9.

13. Whaley AL, Koenen KC (2001) The juvenile-as-adult-criminal debate. J Am Acad Child Adolesc Psychiatry 40: 619-620.

14. Wu ZH, Berenson AB, Wiemann CM (2003) A profile of adolescent females with a history of sexual assault in texas: familial environment, risk behaviors, and health status. J Pediatr Adolesc Gynecol 16: 207-216.

15. Riggs N, Houry D, Long G, Markovchick V, Feldhaus KM (2000) Analysis of 1,076 cases of sexual assault. Ann Emerg Med 35: 358-362.

16. Jänisch S, Meyer H, Germerott T, Albrecht UV, Schulz Y, et al. (2010) Analysis of clinical forensic examination reports on sexual assault. Int $\mathrm{J}$ Legal Med 124: 227-235.

17. Karanfil R, Keten A, Zeren C, Arslan MM, Eren A (2013) Evaluation of sexual assaults in Turkey. J Forensic Leg Med 20: 404-407. 
Citation: Çelikel A, Demirkiran DS, Özsoy S, Zeren C, Arslan MM (2015) Factors Associated with PTSD in Cases of Sexual Assault. J Psychiatry

Page 4 of 4

18. Kar H, Arslan MM, Çekin N, Akcan R, Hilal A (2010) Sexual assault in childhood and adolescence; a survey study. European Journal of Socia Sciences 13: 549-55.

19. Karbeyaz K, GÃ $1 / 4$ nd $\tilde{A} 1 / 4 \mathrm{Z}$ T, Balc $\ddot{A} \pm \mathrm{Y}$, Akkaya H (2012) Forensic psyhiatric reports for victims of sexual assault and consensus problems among expertise institutes. Turk Psikiyatri Derg 23: 255-262.

20. Kessler RC, Sonnega A, Bromet E, Hughes M, Nelson CB (1995) Posttraumatic stress disorder in the National Comorbidity Survey. Arch Gen Psychiatry 52: 1048-1060.

21. Resnick HS, Kilpatrick DG, Dansky BS, Saunders BE, Best CL (1993) Prevalence of civilian trauma and posttraumatic stress disorder in a representative national sample of women. J Consult Clin Psychol 61: 984-991.

22. Ehlers A, Clark DM (2000) A cognitive model of posttraumatic stress disorder. Behav Res Ther 38: 319-345.

23. Dembo R, Williams L, Schmeidler J (1993) Gender differences in mental health service needs. J Prison Jail Health12: 73- 101

24. Horowitz K, Weine S, Jekel J (1995) PTSD symptoms in urban adolescent girls: compounded community trauma. J Am Acad Child Adolesc Psychiatry 34: 1353-1361.

25. Giaconia RM, Reinherz HZ, Silverman AB, Pakiz B, Frost AK, et al. (1995) Traumas and posttraumatic stress disorder in a community population of older adolescents. J Am Acad Child Adolesc Psychiatry 34: 1369-1380.

26. Oquendo MA, Friend JM, Halberstam B, Brodsky BS, Burke AK, et al. (2003) Association of comorbid posttraumatic stress disorder and major depression with greater risk for suicidal behavior. Am J Psychiatry 160: 580-582.

27. Huang G, Zhang Y, Momartin S, Cao Y, Zhao L (2006) Prevalence and characteristics of trauma and posttraumatic stress disorder in female prisoners in China. Compr Psychiatry 47: 20-29.

28. O'Leary P1, Coohey C, Easton SD (2010) The effect of severe child sexual abuse and disclosure on mental health during adulthood. J Child Sex Abus 19: 275-289.

29. Evans E, Hawton K, Rodham K (2005) Suicidal phenomena and abuse in adolescents: a review of epidemiological studies. Child Abuse Negl 29: 45-58.

30. Kocabasoglu N, Özdemir S (2005) An overwiev of the rating scales used in posttraumatic stress disorder.New Symposium 43: 173-78.

31. Stein MB, Walker JR, Hazen AL, Forde DR (1997) Full and partial posttraumatic stress disorder: findings from a community survey. Am J Psychiatry 154: 1114-1119.

32. Kaya B (2004) Post-traumatic stress disorder and concept of subsyndrome. Anadolu Psikiyatri Derg 5: 231-38.

33. Adams JA (2011) Medical evaluation of suspected child sexual abuse: 2011 update. J Child Sex Abus 20: 588-605.

34. Watkeys JM, Price LD, Upton PM, Maddocks A (2008) The timing of medical examination following an allegation of sexual abuse: is this an emergency? Arch Dis Child 93: 851-856. 